Revta brasil. Bot., São Paulo,V.24, n.4 (suplemento), p.577-586, dez. 2001

\title{
Aspectos históricos do Jardim Botânico de São Paulo
}

\author{
YURI TAVARES ROCHA ${ }^{2,4}$ e FELISBERTOCAVALHEIRO ${ }^{3}$
}

(recebido: 6 de setembro de 2000; aceito: 11 de julho de 2001)

\begin{abstract}
The historical aspects of the Botanical Garden of São Paulo). Among the gardens created by men, the botanical garden can be considered as one of the most important. It has many functions such as scientific, educational, social, aesthetical, historical and ecological. The contemporary Botanical Garden of São Paulo was officially established in 1938 with all the functions mentioned above, but the record of its history lacks a revision. The history of the Botanical Garden of São Paulo has shown some frustrated attempts to initially establish the Garden and then to change its original site. Two areas for the construction of the Garden were the most relevant to its history: the site where it was initially conceived, between 1799 and 1838, which today is known as Parque da Luz, and the site where it is now present, since 1928, at the Parque Estadual das Fontes do Ipiranga (PEFI). There were other botanical gardens at São Paulo between 1896 and 1928 such as Horto Botânico da Cantareira, Horto Botânico Oswaldo Cruz and Horto Botânico do Museu Paulista. Nowadays, only the Botanical Garden at PEFI remains. The history of the Botanical Garden of São Paulo is associated with the history of a governmental scientific research institution, the Instituto de Botânica, which is presently responsible for its administration.
\end{abstract}

RESUMO - (Aspectos históricos do Jardim Botânico de São Paulo). Dentre os jardins criados pelo homem, destaca-se o jardim botânico, que possui diversas funções: científica, educacional, social, estética, histórica e ecológica. $\mathrm{O}$ atual Jardim Botânico de São Paulo, fundado oficialmente em 1938, apresenta todas essas funções, mas o registro de sua história carecia de revisão e atualização. A história do Jardim Botânico está repleta de tentativas frustradas de implantação e de mudanças de local de instalação, sendo os dois mais importantes na sua história: o local que abrigou o primeiro Jardim Botânico de São Paulo, entre 1799 e 1838, onde está atualmente o Parque da Luz, e o local onde está desde 1928, no Parque Estadual das Fontes do Ipiranga (PEFI). Outros jardins botânicos de São Paulo no período de 1896 a 1928 foram: Horto Botânico da Cantareira, Horto Botânico Oswaldo Cruz e Horto Botânico do Museu Paulista. A história do Jardim Botânico de São Paulo está ligada à história do Instituto de Botânica, responsável por sua administração desde sua criação.

Key words - Botanical garden, landscape, history, São Paulo

\section{Introdução}

Dentre os jardins criados pelo homem, destaca-se o jardim botânico, que possui diversas funções: científica, educacional, social, estética, histórica e ecológica. Os jardins botânicos são antigos; existiram na Mesopotâmia, no Egito Antigo e na América Pré-Colombiana (Sousa 1976) e mantinham, principalmente, plantas medicinais que já eram objeto de estudos e observações, além de serem espaço de convívio para suas comunidades.

1. Parte da dissertação de mestrado de Yuri Tavares Rocha

2. Instituto de Botânica, Seção de Ecologia, Caixa Postal 4005, 01061-970 São Paulo, SP, Brasil.

3. Universidade de São Paulo, Faculdade de Filosofia, Letras e Ciências Humanas, Departamento de Geografia, Caixa Postal 2530, 01060-970 São Paulo, SP, Brasil.

4. Autor para correspondência: yuritr@hotmail.com
O primeiro jardim botânico ocidental, que teve como objetivo manter coleções de plantas para estudos preliminares e ensino, foi o criado junto ao Liceu próximo a Atenas (Grécia) pelo "pai" da Botânica, Teofrasto, cerca de 370-285 a.C. (Bye 1994). Depois deste, o jardim botânico reapareceu na Europa somente no século XVI; em 1543, Luca Ghini fundou o primeiro jardim botânico moderno, o Real Orto Botanico della Real Universitá di Pisa, Itália; também foi o primeiro a usar estufas de vidro para cultivar plantas exóticas e a estabelecer um herbário para estudo taxonômico (Uphof 1941, Bye 1994).

Importantes jardins botânicos foram criados nos séculos XVI e XVII: 1545 , o de Pádua e de Florença (Itália); 1593, o de Montpellier (França) e de Heidelberg (Alemanha); 1621, o de Oxford (Inglaterra); 1635, o de Paris (França); 1646, o de Berlim (Alemanha); 1655, o de Upsala (Suécia), entre outros (Bye 1994). Nesses séculos, os jardins botânicos criados se tornaram centros de experimentação, ensino e estudo; seus arranjos 
paisagísticos visavam, principalmente, a praticidade do ordenamento das plantas em gêneros e ou famílias botânicas e suas exigências de cultivo, o que significou, em certa medida, não adotar a estética dos jardins renascentistas e barrocos (Tomasi 1991).

A primeira iniciativa para formar um jardim botânico no Brasil foi do príncipe Maurício de Nassau, em Recife (Pernambuco), no século XVII; esse jardim existiu junto ao Palácio de Friburgo entre 1637 e 1644 (Hoehne et al. 1941). Porém, foi apenas no final do século XVIII que foram emitidas instruções portuguesas para criação dos primeiros jardins botânicos brasileiros em Belém, Olinda, Ouro Preto, Salvador, Goiás e São Paulo (Lopes 1997). O primeiro efetivamente estabelecido foi o Jardim Botânico de Belém em 1796 (Segawa 1996); nele, foram introduzidas plantas da Guiana Francesa (Teixeira 1988), incluindo-se o café. Atualmente, existe a Rede Brasileira de Jardins Botânicos, criada em 1991; há 26 instituições listadas no Diretório dos Jardins Botânicos Brasileiros (2000). Indubitavelmente, o Jardim Botânico do Rio de Janeiro, criado em 1808 por Dom João VI, é o mais importante do país e de grande expressão internacional pela sua coleção de plantas vivas (cerca de 8 mil espécies e 35 mil exemplares), principalmente de espécies tropicais (Rodrigues 1989, Michahelles 2000).

Um jardim botânico é um jardim que apresenta coleções de plantas vivas (maioria) ordenadas, documentadas e identificadas, aberto ao público com finalidades de educação, conservação, pesquisa, recreação e prestação de serviços, exercendo função no desenvolvimento cultural, educacional, científico e econômico (Heywood 1985, 1990, Bye 1994).

O atual Jardim Botânico de São Paulo, fundado oficialmente em 1938, apresenta essas funções mas o registro de sua história carecia de revisão e atualização, que foram objeto deste estudo.

\section{Material e métodos}

O atual Jardim Botânico de São Paulo está localizado na zona sudeste do município de São Paulo e inserido na área do Instituto de Botânica de 164,45 ha, que são subdivididos em reserva florestal - 116 ha; área com as instalações administrativas e seções técnicas do Instituto - 11,94 ha; e área de visitação pública do Jardim Botânico - 36,30 ha (São Paulo 1990). Considerou-se que esta área de visitação pública foi superestimada, adotando-se a definida por Rocha \& Cavalheiro (2000b), que é de aproximadamente 23 ha; uma parte da reserva florestal do Instituto de Botânica contígua à área de visitação, de aproximadamente 30 ha, também poderia ser acessível ao público por meio de trilhas. Assim, de acordo com Rocha \& Cavalheiro (2000b), a área total do Jardim Botânico de São Paulo é de 53 ha. O Jardim Botânico se encontra dentro do Parque Estadual das Fontes do Ipiranga (PEFI), que está ao redor dos paralelos 23⒊' S e 46 $37^{\prime} \mathrm{W}$, tem altitude média de $798 \mathrm{~m}$ e área total de 549,31 ha (Reis 1998). O clima é mesotérmico de inverno seco tipo Cwb, apresentando precipitação anual acima de $1000 \mathrm{~mm}$, temperatura média do mês mais frio de $18{ }^{\circ} \mathrm{C}$ e temperatura média do mês mais quente de $22{ }^{\circ} \mathrm{C}$ (Struffaldi-de Vuono 1985). A área pertence à província do Planalto Atlântico, zona do Planalto Paulista, na Bacia Sedimentar de São Paulo, de origem flúvio-lacustre; na reserva florestal, o solo é do tipo Latossolo Vermelho Amarelo fase rasa, proveniente de transformações de filitos, xistos e rochas granito-gnáissicas (Reis 1998). Sua vegetação nativa pode ser caracterizada como sendo uma extensão da floresta atlântica de encosta com elementos de floresta mesófila (Struffaldi-de Vuono 1985).

Realizou-se o levantamento da história do Jardim Botânico de São Paulo consultando material iconográfico (representações gráficas e fotografias; as principais podem ser encontradas em Rocha 1999) e bibliografia referente a estudos sobre jardins botânicos e sobre o Jardim Botânico de São Paulo. Essa metodologia também foi adotada nos estudos realizados por Terra (1993), Kliass (1993), Goecke (1979), Moynihan (1980), Christopher (1981), Lavôr (1983), Rodrigues (1989), Howard (1996) e Cachafeiro (1997a, b, c).

\section{Resultados}

A história do Jardim Botânico de São Paulo está repleta de tentativas frustradas de implantação e de mudanças de local, sendo dois mais importantes na sua história: a primeira sede, onde foi instalado e formado entre 1799 e 1838, local atualmente ocupado pelo Parque da Luz, e a sede atual desde 1928, que se encontra no Parque Estadual das Fontes do Ipiranga. No período de 1896 a 1928 existiram em São Paulo os hortos botânicos da Cantareira, Oswaldo Cruz e do Museu Paulista, que significaram tentativas de criação de um jardim botânico em São Paulo, apesar de adotarem a denominação de horto botânico. Desde 1917, a história do Jardim Botânico de São Paulo, mesmo na forma incipiente de horto botânico, esteve ligada à história do Instituto de Botânica, responsável por sua administração.

Primeiro Jardim Botânico de São Paulo (17991838) - Desde a fundação da cidade de São Paulo, no século XVI, o padre jesuíta José de Anchieta 
pretendia fazer um jardim com plantas do "altiplano piratininguense e do vicentino litoral", onde seriam estudadas quanto à sua utilidade (Hoehne et al. 1941). Porém, somente após dois séculos é que essa intenção começou a ganhar forma.

No século XVIII, a História Natural teve grande desenvolvimento na Europa enfocando, principalmente, a descrição e classificação de plantas e animais; também surgiu um encantamento do europeu frente às flora e fauna do Novo Mundo, levando-o a coletar, catalogar e colecionar minerais, vegetais e animais e a formar herbários, jardins botânicos e coleções (Prestes 2000). A obra Flora Fluminensis, elaborada pelo Frei José Mariano da Conceição Vellozo e apresentada por ele mesmo em 1790 à Corte em Lisboa, é um exemplo nacional dessa época em que foram iniciadas as investigações sobre a natureza brasileira (Borgmeier 1999).

Em Portugal, o incentivo às ciências naturais estava inserido dentro de uma política de aproveitamento dos recursos naturais de seus domínios do século XVIII; assim, o Ministro da Marinha e Ultramar da Rainha D. Maria I, D. Rodrigo de Souza Coutinho, mandava os governadores do Brasil enviarem amostras de produtos naturais e sementes de plantas de interesse econômico ao Real Jardim Botânico da Ajuda, localizado em Lisboa (Lopes 1997).

No final do século XVIII, tentativas para criação de jardins botânicos no Brasil foram feitas. A primeira foi efetivada com o Jardim Botânico do Pará, cuja criação foi ordenada por Carta Régia de D. Maria I de 04 de novembro de 1796 e cuja instalação foi terminada em 1798 (Segawa 1996, Lopes 1997). Um catálogo de plantas cultivadas nesse jardim botânico foi enviado ao Governador da Capitania da Bahia em 19 de novembro de 1798 por D. Rodrigo de Souza Coutinho, para que também fosse criado em Salvador um jardim botânico semelhante ao do Pará (Rocha \& Cavalheiro 2000a).

O Jardim Botânico de São Paulo foi criado a partir de uma "ordem" registrada no documento "Memoria Relativa ao Estabelecimento do Hospital Militar e Jardim Botanico desta Cidade", de 14 de janeiro de 1803, arquivado na Biblioteca Nacional (Brasil 1803), o qual relata que pelo "Aviso de 19 de Novembro de 1799, pelas quaes" (ordens) foi "mandado estabelecer e crear hum Horto Botanico á imitação do que se havia feito no Pará". Esse documento foi assinado por Antonio Manoel de Mello Castro e Mendonça, Governador da Capitania de São Paulo, terminando com a confusão entre as datas (Rocha \& Cavalheiro 2000a). Alguns pesquisadores (Martins 1911, Kliass 1993, entre outros) confundiram a data de criação do Jardim Botânico de São Paulo com os de Belém e Salvador, como sendo de 1796 ou 1798.

Em cumprimento a esse aviso, escolheu-se a área para o jardim botânico em terras devolutas no Campo da Luz. Em 1797, também nessa área foi iniciado um quartel para a artilharia (Martins 1911, Marques 1954). Ao invés de se terminar o quartel, optou-se por construir um hospital militar junto ao jardim. Mesmo fato ocorreu em 1765 em Saint Vincent (Pequenas Antilhas, Caribe), quando esteve sob o domínio britânico, para ajudar o hospital na obtenção de remédios; assim foi criado o Saint Vincent Botanical Garden (Howard 1996).

Por causa da prioridade dada ao hospital, o Jardim Botânico de São Paulo somente foi concluído e aberto ao público em 1825 (Martins 1911, Bruno 1953a, Marques 1954, Danon \& Toledo 1974). Marcílio (1973) e Kidder (1839) registraram a existência de um jardim botânico em São Paulo em seus relatos, além de comentarem sobre algumas de suas plantas e ou sobre seu arranjo paisagístico nas primeiras décadas do século XIX.

A partir de 1830 começou um período de dificuldades para o jardim botânico: passagem por diversas administrações, loteamento e venda de áreas, utilização como pastagem e falta de conhecimentos sobre a temática jardim botânico de quem o administrava (Bruno 1953b). Tudo isso contribuiu para que a Assembléia Legislativa Provincial, em 1838, mudasse o nome de Jardim Botânico para Jardim Público (Martins 1911, Hoehne et al. 1941, Marques 1954, Danon \& Toledo 1974). Atualmente, a área de 1,4 ha ocupada pelo Parque da Luz significa $13 \%$ da área originalmente ocupada pelo Jardim Botânico.

Infelizmente, apesar de no final do século XVIII a instituição de jardins botânicos ter se tornado "projeto oficial para abrigar espécies de plantas medicinais além de outras de valor econômico, como as de utilidade para a construção naval" e, da referência de 1810 do "Discurso sobre a utilidade da instituição de Jardins nas principais 
províncias do Brasil”, escrita por Manuel Arruda da Câmara, um dos grandes naturalistas lusobrasileiros (Prestes 2000), a maioria dos jardins botânicos brasileiros iniciados nesse período não vingou, inclusive o de São Paulo. O único a prevalecer e crescer foi o do Rio de Janeiro. O Jardim Botânico de São Paulo que existiu até 1838 não pode ser comparado aos seus congêneres europeus contemporâneos nem recebeu os incentivos de que foi alvo o do Rio de Janeiro.

Horto Botânico da Cantareira (1896-1917) - A primeira intenção de formar outro jardim botânico na cidade de São Paulo foi a apresentada pelo naturalista Dr. Alberto Löfgren em 1888; o projeto foi votado na Assembléia Provincial em 6 de março e não foi aprovado; previa a retomada das funções de jardim botânico do Jardim da Luz, cuja administração ficou a cargo do próprio Löfgren em 1889 (Kliass 1993).

Mas em 1896 houve a concretização dessa intenção com a fundação de um horto botânico próximo ao Parque da Cantareira, em área desapropriada de 174 ha, pelo mesmo Löfgren, na época em que trabalhou como botânico na Comissão Geográfica e Geológica de São Paulo (Hoehne 1940). A formação desse horto foi recomendada por uma comissão técnica formada por Orville Derby, Francisco Ramos de Azevedo e Alberto Löfgren. Para Teixeira (1988), a data da fundação desse Horto é de 1898; porém, em relatório de 1905, foi feita referência à morte de um dos velhos muares comprados da Companhia Viação em 1896 (Löfgren 1905).

Uma das realizações desse Horto Botânico, juntamente com a Comissão Geográfica e Cartográfica, foi a elaboração de uma relação de plantas úteis nativas e exóticas recomendadas para plantio no Estado (Löfgren 1901). A organização geral desse Horto foi feita somente em 1909 e tinha entre seus objetivos: estudo científico da flora paulista, organização de herbário e museu botânico, formação de parques e bosques de espécies nativas e exóticas, estudo sobre a aclimatação e o aproveitamento de essências florestais, produção e distribuição de mudas aos interessados em reconstituir ou formar matas e bosques em suas propriedades (São Paulo 1909).

Também essa segunda tentativa de formar um jardim botânico foi frustrada por decisões que "priorizaram aspectos econômicos ao invés dos científicos" (Hoehne 1940). Assim, mesmo tendo funcionado como horto botânico e tido renome nacional e internacional (Teixeira 1988), foi transformado em horto florestal em 1917 (Hoehne et al. 1941).

Nesse mesmo período, começo do século XX, Hermann von Ihering (diretor do Museu Paulista ou do Ipiranga entre 1893 e 1916) e Hermann Luederwaldt (naturalista e botânico do Museu) organizaram um horto botânico nos fundos do Museu, onde foram introduzidas inúmeras espécies indígenas e exóticas (Hoehne 1925, Teixeira 1988). Pretendiam nesse pequeno horto "expôr typos seleccionados da flora de S. Paulo, formar um ponto para pesquisas cientificas, cultivar as plantas indigenas uteis e decorativas e criar um meio esthetico e alegre em que o estudo se tornasse attrahente e agradavel e não insípido e enfadonho" (Hoehne 1925). Porém, com a saída de von Ihering da direção do Museu em 1916, o horto não teve muitos avanços e passou a ser utilizado como jardim. Tornou-se novamente um horto botânico entre 1922 e 1928.

Horto Botânico Oswaldo Cruz (1917-1922) - O botânico Frederico Carlos Hoehne veio do Rio de Janeiro, onde trabalhava no Museu Nacional e na Comissão Rondon, para São Paulo em 1917, para instalar um horto botânico para estudos de plantas medicinais no Instituto Butantã, a convite do seu diretor, Dr. Vital Brazil (Hoehne 1943). Esse horto recebeu o nome de Horto Botânico Oswaldo Cruz; em 1922, já possuía mais de 300 espécies de plantas, relatadas na obra "Catálogo do herbário e das espécies cultivadas no Horto Oswaldo Cruz" (Hoehne 1940, 1943).

O local escolhido para a implantação do Horto foi em frente à sede do Instituto Butantã; pertencia à Seção de Botânica criada no Instituto, que passou a organizar um acervo de material herborizado (início do herbário científico) e uma biblioteca especializada; tal Seção produziu trabalhos referentes a plantas medicinais, principalmente de espécies da flora indígena, sendo que muitas espécies eram novas para a ciência (Hoehne 1925, Teixeira 1988). Também funcionou ali o primeiro museu botânico de plantas medicinais e tóxicas, fundado em 1919 (Hoehne 1943).

Em 1917, a Seção de Botânica assumiu a direção da Estação Biológica do Alto da Serra de 
Paranapiacaba; essa Estação foi fundada por Hermann von Ihering que, em 1909, quando diretor do Museu Paulista, adquiriu com recursos particulares uma área de mata atlântica primitiva, transformando-a em estação biológica, vendida ao Governo do Estado em 1912 (Teixeira 1988).

Em 1922, quando o Dr. Rudolf Krauss assumiu a diretoria do Instituto Butantã, o Horto Botânico perdeu suas finalidades originais e a Seção de Botânica, com pessoal, herbário e biblioteca, dirigida por Hoehne, foi transferida para o Museu Paulista, juntamente com a Estação Biológica do Alto da Serra (Hoehne 1925, 1949, Teixeira 1988). Ficou a cargo dessa Seção o antigo horto situado nos fundos do Museu, fundado por Ihering e Luederwaldt. Os campos de cultura do Horto Botânico Oswaldo Cruz ficaram ainda sob a administração da Seção de Botânica até sua permanência no Museu Paulista; posteriormente, foram perdidos (Hoehne 1925, 1949).

Horto Botânico do Museu Paulista (1922-1928) - O antigo horto nos fundos do Museu foi ampliado e se tornou o Horto Botânico do Museu Paulista; era dividido em "duas regiões maiores, phytophysionomicamente diversas: a das mattas e a dos campos", ocupando uma área de $5 \mathrm{ha}$; apresentava vários caminhos que conduziam às coleções de plantas de regiões lacustre, de campo e litorânea, além de coleções de cactáceas, palmeiras e bromélias e de uma área de mata nativa preservada, chamada de "caapão" (Hoehne 1925).

Apesar de pequeno, esse horto possuía boa representatividade da flora paulista e coleções interessantes. Mesmo estando nos fundos do Museu Paulista, local muito visitado, Hoehne apontava que o contrário acontecia ao Horto: "tão esquecido tem sido pelos paulistas, a ponto de muitos nem ao menos terem conhecimento de sua existência" (Hoehne 1925). Posteriormente esse horto perdeu suas características e foi transformado em parque público (Teixeira 1988).

Em nova mudança, a Seção de Botânica, juntamente com o horto que se manteve nos fundos do Museu Paulista, foi transferida em 1928 para o Instituto Biológico de Defesa Agrícola e Animal, formando a Seção de Botânica e Agronomia com Hoehne na chefia, considerada serviço autônomo em 1934 (Hoehne 1940, 1949). Em 1938, o Interventor Federal Dr. Adhemar de Barros criou o
Departamento de Botânica do Estado, que administraria o Jardim Botânico de São Paulo (Hoehne 1949).

Atual Jardim Botânico de São Paulo (1928-2000) Em 1895, a Repartição de Águas do Estado iniciou a desapropriação de matas, capoeiras e pequenas chácaras situadas no atual bairro da Água Funda com a finalidade de preservar a vegetação da área de captação de águas, que abasteciam bairros da zona leste da cidade de São Paulo; essa área contém as nascentes do riacho Ipiranga (Hoehne 1949, Teixeira 1988) e ficou conhecida por Mata do Governo, Parque da Água Funda, das cabeceiras do Ipiranga ou do Estado, atualmente denominada Parque Estadual das Fontes do Ipiranga.

A função de manancial foi abandonada em 1928 por perigo de poluição e pelo baixo volume de água. Cerca de 220 ha da área total ficaram sob os cuidados da Seção de Botânica do Instituto Biológico, "compreendidos entre as cercas que limitam com a Vila Moraes e a estrada pública que vai em demanda do Tabuão e São Bernardo do Campo" (Hoehne et al. 1941, Hoehne 1949, 1951).

Com o objetivo de formar um parque público na área do Parque do Estado, já haviam sido formados dois grandes lagos desde 1929 (Hoehne 1949), um dentro do atual Zoológico e o outro entre o Zoológico e o Jardim Botânico (Lago das Garças).

Uma vez que esse parque público não foi criado, houve a proposta de organizar, nessa mesma área, um jardim botânico com a finalidade de "proporcionar área de recreação à população e de estabelecer produção e exposição de plantas ornamentais da flora indígena"; para isso, foi encarregada a empresa Mario Whately \& Co. para elaborar um projeto de instalação do Jardim Botânico (Hoehne et al. 1941). Não se obteve nenhum registro ou documento que explicitasse a autoria de um arquiteto ou engenheiro do projeto paisagístico elaborado para o jardim botânico.

O plano de urbanização da área estabeleceu a abertura de caminhos, ruas e avenidas, a construção de duas estufas (figura 1) e do Jardim de Lineu (figura 1) e o estabelecimento do início do Orquidário do Estado, inaugurado oficialmente em 1930, embrião do Jardim Botânico (Teixeira 1988). Já em 1929 o orquidário instalado de maneira provisória recebia visitas públicas (Hoehne et al. 1941). 


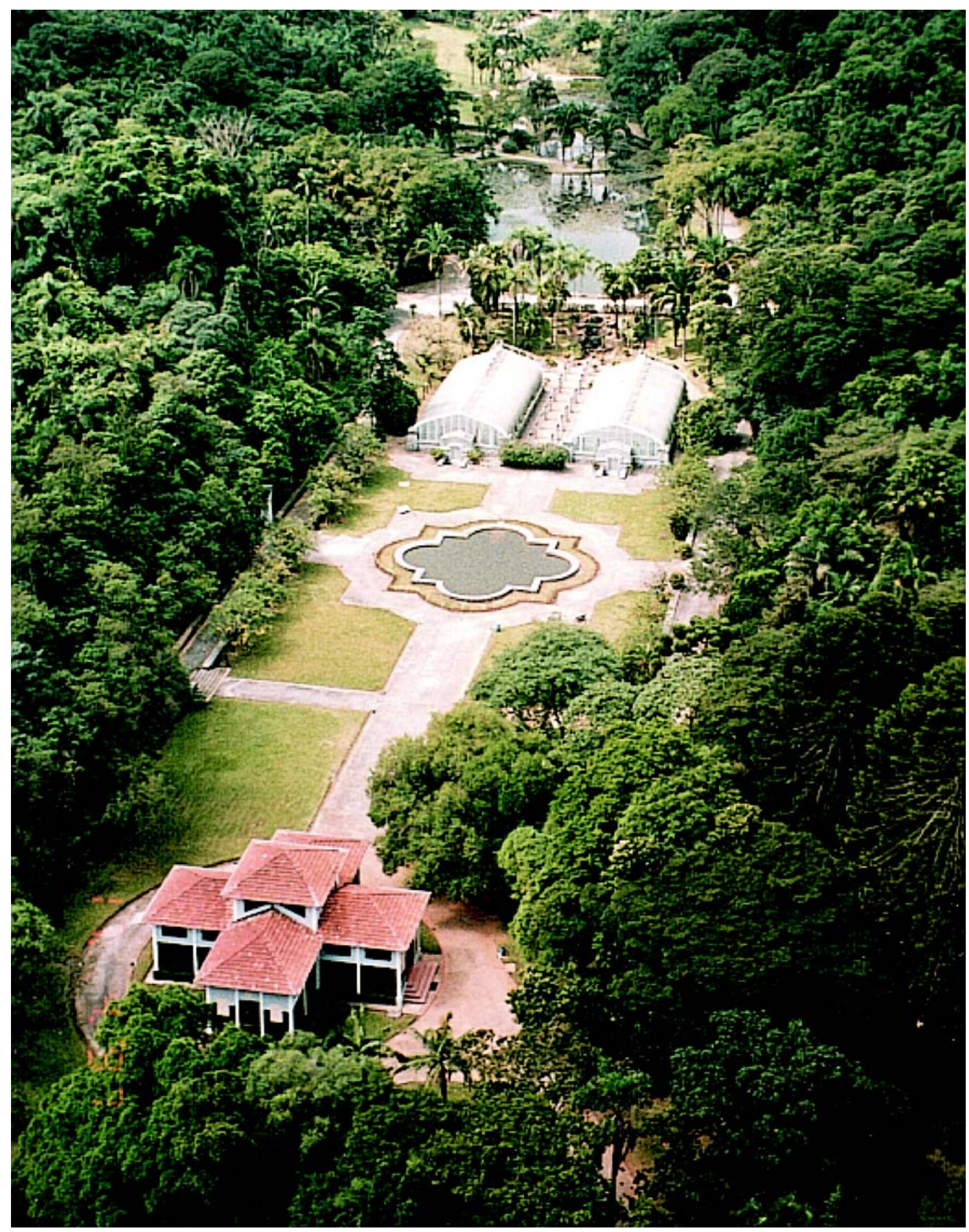

Figura 1. Vista aérea de parte do Jardim Botânico de São Paulo. No primeiro plano está o Museu Botânico Dr. João Barbosa Rodrigues; no segundo plano, o Jardim de Lineu e as estufas; ao fundo, o Lago das Ninféias; e, no entorno, parte da floresta pluvial atlântica (Foto de Joceli Adair da Silva de 1997). 
Porém, dificuldades para a instalação completa do Jardim Botânico apareceram depois de 1930, sendo realizadas obras de forma lenta, tais como abertura da Alameda Fernando Costa, drenagem de terrenos, construção de novo portão e de casas da administração e da guarda, laboratórios, abertura de caminhos e aquisição de novas coleções (Hoehne et al. 1941).

A concepção do Jardim Botânico foi baseada no estilo naturalista. Uma exceção é o Jardim de Lineu, inspirado numa parte do Jardim Botânico de Upsala (Suécia), fundado por Lineu quando era professor de Botânica da Universidade de Upsala (São Paulo 1990). Como o Jardim de Lineu é uma cópia de parte do Jardim de Upsala, é claro que seu desenho simétrico, de inspiração renascentista, apresente um contraste com o estilo naturalista do restante. Para Hoehne (1940), exatamente essa parte diante das estufas precisaria ser modificada quando possível para que "tudo no nosso Jardim Botânico nos fale de coisas nossas, bem brasílicas, para que não se nos diga que não temos idéias originais".

Com a colaboração do Dr. Fernando Costa, então Secretário da Agricultura, Indústria e Comércio, Frederico Carlos Hoehne fundou oficialmente o Jardim Botânico em 1938, quando também foi criado o Departamento de Botânica do Estado, diretamente ligado à mesma Secretaria e que administraria o Jardim (Hoehne 1940, Hoehne et al. 1941). Nessa época, a sede desse Departamento ficava na Avenida Paulista, 2.086.

Outras tarefas executadas na instalação do Jardim Botânico realizadas em 1938 foram a pavimentação das ruas do Jardim e a abertura da Avenida das Palmeiras Reais, alternadas com ipês róseos, conhecida como Alameda Martius (Hoehne et al. 1941).

Em 1940, iniciou-se a construção dos prédios para sediar o Departamento de Botânica, cuja mudança da Avenida Paulista foi concluída em 1942 (Hoehne 1943, Teixeira 1988). Nesse mesmo ano, o Departamento passou a ser denominado de Instituto de Botânica (Hoehne 1943, 1949).

A construção do prédio do Museu Botânico Dr. João Barbosa Rodrigues (figura 1) também foi iniciada em 1940, seguindo um projeto peculiar que possibilitou que as paredes pudessem ser aproveitadas para a colocação de vitrines com as amostras botânicas (Hoehne et al. 1941). Outras edificações existentes na área de visitação são os três pavilhões construídos na década de 1940.

Em 1951, o Jardim de Lineu foi utilizado para a formação do Jardim de Pedras, com plantas rupestres (Hoehne 1955). Atualmente, essa área permanece com o seu aspecto inicial já que as coleções de plantas que compunham o Jardim de Pedras foram perdidas.

No final da década de 1950, foi elaborado pelo paisagista Roberto Burle Marx um anteprojeto paisagístico para o Jardim Botânico, subdividindoo em "hortos temáticos" (São Paulo 1990). Esse anteprojeto já fazia parte do programa de trabalho da gestão do diretor do Instituto em 1959 (Fidalgo 1972) e, posteriormente, passou a ser denominado de Plano Burle Marx.Esse Plano previa a implantação de vários hortos e jardins temáticos: de regiões temperadas e tropicais, de árvores exóticas, de melastomatáceas, de bambus, de trepadeiras, de pteridófitas, de igarapé, de suculentas, para cegos, jardim japonês, de plantas aquáticas, de mata local, de orquídeas, de plantas de brejo, de palmeiras, da região amazônica, do sul da Bahia, do Maranhão, do Piauí; do Espírito Santo, do Paraná, de Santa Catarina, da encosta atlântica, do cerrado/cerradão, do pinheiral, da caatinga e de campo. Também previa hotel para cientistas, pavilhão de exposições, abrigo para visitantes, edificações para a sede do Instituto, Museu da Ciência, além do Museu Botânico, anfiteatro ao ar livre, zona de piquenique, praça de esportes e parque infantil.

A partir de 1962, foram feitas alterações no Jardim Botânico: construção de um prédio de serviços, conhecido como "redondo", hoje destinado a exposições; portaria de visitantes e estacionamento para os veículos dos visitantes fora da área do Jardim Botânico (Milanez 1997).

Em 1963, foi feito um detalhamento parcial do Plano Burle Marx pelo Escritório Roberto Burle Marx; foram produzidas 48 plantas nas escalas 1:2500, 1:2000, 1:1000 e 1:500 (principal escala usada). Também existem plantas de 1967 que tratam do Plano Burle Marx. Todas essas plantas estão arquivadas na mapoteca da biblioteca do Instituto. Apesar de na década de 1960 não ter sido feita nenhuma implantação do Plano Burle Marx, a existência de material produzido nesse período indica que sua execução era pretendida.

Do Plano Burle Marx, apenas os lagos contíguos à Alameda Martius foram implantados, cuja obra foi iniciada em 1970 e concluída em 1972, quando o Jardim Botânico foi reaberto à visitação pública, suspensa durante a realização da obra (Fidalgo 1973). 
Quanto ao número de espécies em sua coleção, em 1943 o Jardim Botânico tinha mais de 1.700 espécies classificadas e descritas (Hoehne 1944). Em 1951, na área em torno das estufas e do Museu Botânico, existiam 344 espécies distribuídas em 54 famílias (Hoehne 1955). Atualmente, não se tem o número exato de espécies mantidas no Jardim Botânico mas, de acordo com o Diretório dos Jardins Botânicos Brasileiros (2000), existem 50.000 espécimes em sua coleção viva.

Quanto às atividades de educação ambiental, são realizadas visitas monitoradas dirigidas aos visitantes, estudantes e público em geral, percorrendo o Jardim, o Museu Botânico e as estufas, além de serem elaboradas exposições e folhetos educativos sobre temas botânicos e ambientais.

Atualmente, os principais atrativos do Jardim Botânico de São Paulo são: Museu Botânico Dr. João Barbosa Rodrigues; Lago das Ninféias (figura 1) Jardim de Lineu; estufa com exposição permanente de plantas, principalmente da mata atlântica; lagos formados pelas nascentes do riacho Ipiranga; Túnel de Bambu; Bosque de Pau-brasil e Orquidário de Visitação Pública (onde também há exposição de bromélias e outras epífitas), além da parte da floresta pluvial atlântica preservada.

\section{Discussão}

A falta de fortalecimento e continuidade do primeiro Jardim Botânico de São Paulo nos moldes da política portuguesa da época para a instituição de jardins botânicos significou um atraso de um século na evolução da ciência botânica dentro de um jardim botânico brasileiro, já que foi descaracterizado em 1838 e somente 100 anos depois é que foi fundado oficialmente $\mathrm{o}$ atual Jardim Botânico de São Paulo. Em nível nacional, esse papel foi muito bem desempenhado pelo Jardim Botânico do Rio de Janeiro fundado em 1808, que pode ter sido favorecido por se encontrar naquela cidade, sede do Reino, depois Império e República.

O estudo sobre os hortos botânicos na cidade de São Paulo foi importante para registrar definitivamente suas existências e para as temáticas jardim botânico, São Paulo e espaços livres urbanos.

A ligação entre o Instituto de Botânica e o atual Jardim Botânico de São Paulo tornou se mínima com o passar das décadas, limitando-se apenas ao caráter administrativo. Uma das causas pode ter sido a implantação de linhas de pesquisa que não envolviam as coleções do Jardim nem seu aumento.

O Instituto de Botânica possui uma equipe profissional formada por engenheiros agrônomos, biólogos, engenheiro, ecólogo, entre outros que vêm contribuindo para a administração do Jardim Botânico de São Paulo, junto com uma equipe de funcionários de apoio capacitados para tal. Entretanto, a equipe é numericamente pequena, face às potencialidades desse bem público. Atualmente, realizam-se esforços para adequá-lo às diretrizes estabelecidas pela Resolução n. 266 do Conselho Nacional do Meio Ambiente (CONAMA), de 3 de agosto de 2000, que trata da regulamentação dos jardins botânicos no Brasil.

Visando aumentar sua visitação, algumas medidas de curto, médio e longo prazos podem ser adotadas como a ampliação do número de exposições durante o ano, divulgação das atrações do Jardim na mídia, realização de cursos de pequena duração sobre temas de interesse do público visitante e colocação do Jardim como parte integrante do circuito turístico da cidade, entre outras.

Quanto à coleção de plantas vivas, o Jardim Botânico pode ser ampliado, mantendo coleção de plantas de sua região, além da conservação de fragmento florestal que já realiza. Assim, poderiam ser implantadas coleções de plantas que ocorriam nos Campos de Piratininga, de plantas rupestres que existiam no Jaraguá ou de plantas encontradas nos campos de Itararé. Nenhum jardim oferece uma amostra dessas formações. Além disso, como jardim botânico regional, o Jardim Botânico de São Paulo poderia servir de mostruário da flora de São Paulo, como sugerido por Hoehne (1940).

As reservas biológicas, pertencentes ao Instituto de Botânica, conceitualmente são unidades de conservação in situ do Jardim Botânico de São Paulo. São três: a de Paranapiacaba, localizada no município de Santo André e em área de floresta pluvial atlântica, está ligada a ele desde 1917, quando da permanência da Seção de Botânica no Museu Paulista; a de Mogi Guaçu, localizada no município do mesmo nome e em área de cerrado, foi transferida do Instituto Florestal em 1970 (Teixeira 1988); e a reserva biológica na sede do Instituto, considerada 
sua reserva florestal e parte do Parque Estadual das Fontes do Ipiranga. A vegetação existente nessas reservas biológicas, representativas dos principais ecossitemas do Estado de São Paulo, amplia o potencial científico do Jardim Botânico de São Paulo, possibilitando a realização de um dos papéis mais importantes a ser desempenhado por um jardim botânico moderno, que é a conservação da biodiversidade (Bramwell 1990).

\section{Referências bibliográficas}

BORGMEIER, T. 1999. Introdução sobre a Flora Fluminensis. In Flora Fluminensis - estudos preliminares (J.M.C. Vellozo). Secretaria de Estado de Meio Ambiente e Desenvolvimento Sustentável, Rio de Janeiro, p.11-15.

BRAMWELL, D. 1990. Conserving biodiversity in the Canary Islands. Annals of the Missouri Botanical Garden 77:28-37.

BRASIL, Biblioteca Nacional. 1803. Memoria relativa ao estabelecimento do Hospital Militar e Jardim Botanico desta Cidade, 14 jan. 1803. Assinada por Antonio Manoel de Mello Castro e Mendonça, governador e capitão geral da capitania de São Paulo.

BRUNO, E.S. 1953a. História e tradições da cidade de São Paulo: arraial dos sertanistas (1554-1828). José Olympio, Rio de Janeiro, v.1.

BRUNO, E.S. 1953b. História e tradições da cidade de São Paulo: burgo dos estudantes (1828-1872). José Olympio, Rio de Janeiro, v.2.

BYE, R. 1994. Historia de los jardines botanicos: evolucion de estilos, ideas y funciones. Chapingo (Serie Horticultura) 2:43-53.

CACHAFEIRO, M.S. 1997a. Um jardim histórico em Porto Alegre. Tempo Verde 155: 26.

CACHAFEIRO, M.S. 1997b. Do Campo da Várzea ao Parque Farroupilha: um local de socialidade em Porto Alegre. Tempo Verde 157:26.

CACHAFEIRO, M.S. 1997c. Parque Farroupilha: um espaço público por excelência. Tempo Verde 158:22-23.

CHRISTOPHER, T. 1981. The public gardens of ancient Rome. Garden 5:10-13.

DANON, D.D. \& TOLEDO, B.L. 1974. São Paulo: "Belle Époque”. Nacional/EDUSP, São Paulo.

DIRETÓRIO DOS JARDINS BOTÂNICOS BRASILEIROS. 2000. Rede Brasileira de Jardins Botânicos/Expressão e Cultura, Rio de Janeiro.

FIDALGO, O. 1972. Relatório das atividades do Instituto de Botânica no período de 1956-1971. Secretaria da Agricultura, São Paulo.

FIDALGO, O. 1973. Relatório da gestão de Oswaldo Fidalgo: 16 de abril de 1969 a $1^{\circ}$ de janeiro de 1973. Secretaria da Agricultura, São Paulo.

GOECKE, M. 1979. Der Barockpark zu Jersbek. Garten + Landschaft 89:162-166.

HEYWOOD, V.H. 1985. Botanic gardens conservation strategy. World Wide Fund for Nature, Gland.
HEYWOOD, V.H. 1990. Estratégia dos jardins botânicos para a conservação. Jardim Botânico do Rio de Janeiro/ IBAMA, Rio de Janeiro.

HOEHNE, F.C. 1925. Album da Secção de Botanica do Museu Paulista. Methodista, São Paulo.

HOEHNE, F.C. 1940. Relatório anual do Departamento de Botânica: exercício de 1939. Secretaria da Agricultura, Indústria e Comércio, São Paulo.

HOEHNE, F.C. 1943. Relatório anual do Instituto de Botânica (ex-Departamento de Botânica): exercício de 1942. Secretaria da Agricultura, Indústria e Comércio, São Paulo.

HOEHNE, F.C. 1949. Relatório anual do Instituto de Botânica: exercício de 1948. Secretaria da Agricultura, São Paulo.

HOEHNE, F.C. 1951. Relatório anual do Instituto de Botânica: exercício de 1950. Secretaria da Agricultura, São Paulo.

HOEHNE, F.C. 1955. Relatório anual do Instituto de Botânica: exercício de 1951. Secretaria da Agricultura, São Paulo.

HOEHNE, F.C., KUHLMANN, M. \& HANDRO, O. 1941. O Jardim Botânico de São Paulo. Secretaria da Agricultura, Indústria e Comércio, São Paulo.

HOWARD, R.A. 1996. The St. Vincent Botanical Garden: the early years. Harvard Papers in Botany 8:1-6.

KIDDER, D.P. 1839. A brancura dos prédios contrasta admiravelmente com seus telhados vermelhos. In Memória da cidade de São Paulo: depoimentos de moradores e visitantes (E.S. Bruno, org.). Prefeitura Municipal de São Paulo, São Paulo, 1981, p.55-57.

KLIASS. R.G. 1993. Parques urbanos de São Paulo e sua evolução na cidade. Pini, São Paulo.

LAVÔR, J.C.N. 1983. Histórico do Jardim Botânico do Rio de Janeiro. Instituto Brasileiro de Desenvolvimento Florestal, Rio de Janeiro.

LÖFGREN, A. 1901. As plantas úteis indígenas ou para introduzir. Boletim da Agricultura 2: 169-186.

LÖFGREN, A. 1905. Resumo dos trabalhos efetuados no Horto Botânico durante o mês de janeiro de 1905. Boletim da Agricultura 6:32-34.

LOPES, M.M. 1997. O Brasil descobre a pesquisa científica: os museus e as ciências naturais no século XIX. Hucitec, São Paulo.

MARCÍLIO, M.L. 1973. A cidade de São Paulo: povoamento e população, 1750-1850. Pioneira/EDUSP, São Paulo.

MARQUES, M.E.A. 1954. Apontamentos históricos, geográficos, biográficos, estatísticos e noticiosos da Província de São Paulo. Biblioteca Histórica Paulista, São Paulo, v.2.

MARTINS, A.E. 1911. São Paulo Antigo (1554 a 1910). Livraria Francisco Alves, Rio de Janeiro, v.1.

MICHAHELLES, K. 2000. Instituto de Pesquisas Jardim Botânico do Rio de Janeiro. EMC Edições, Rio de Janeiro.

MOYNIHAN, E.B. 1980. Paradise as a garden. Garden 4: 4-8.

PRESTES, M.E.B. 2000. A investigação da natureza no Brasil colônia. Annablume/FAPESP, São Paulo. 
REIS, L.A.M. 1998. Parque Estadual das Fontes do Ipiranga: utilização e degradação. Trabalho de Graduação Individual, Universidade de São Paulo, São Paulo.

ROCHA, Y.T. 1999. Dos antigos ao atual Jardim Botânico de São Paulo. Dissertação de mestrado, Universidade de São Paulo, São Paulo.

ROCHA, Y.T. \& CAVALHEIRO, F. 2000a. O primeiro Jardim Botânico de São Paulo, Brasil (1799-1838). Actas do Congresso Luso-brasileiro "Portugal-Brasil: Memórias e Imaginários" 2:349-362.

ROCHA, Y.T. \& CAVALHEIRO, F. 2000b. Unidades de paisagem do Jardim Botânico de São Paulo. GEOUSP 7:91-116.

RODRIGUES, J.B. 1989. Hortus fluminensis ou breve notícia sobre as plantas cultivadas no Jardim Botânico do Rio de Janeiro: para servir de guia aos visitantes. Expressão e Cultura, Rio de Janeiro.

SÃO PAULO (Estado). 1909. Decreto n. 1749, 30 jun. 1909 Organiza o Horto Botânico e Florestal, extingue a Seção de Botânica da Diretoria de Agricultura e dá outras providências. Boletim da Agricultura (Atos Oficiais) 10:419-422.

SÃO PAULO (Estado). 1990. Plano de recuperação do Jardim Botânico de São Paulo. Secretaria do Meio Ambiente, São Paulo.
SEGAWA, H. 1996. Ao amor do público: jardins no Brasil. Studio Nobel/FAPESP, São Paulo.

SOUSA, H.M. 1976. Os jardins botânicos. Suplemento Agrícola 1084:7.

STRUFFALDI-DE VUONO, Y. 1985. Fitossociologia do estrato arbóreo da floresta da Reserva Biológica do Instituto de Botânica de São Paulo, SP. Tese de doutorado, Universidade de São Paulo, São Paulo.

TEIXEIRA, A.R. 1988. Resenha histórica do Instituto de Botânica de São Paulo. Ciência e Cultura 40:1045-1054.

TERRA, C.G. 1993. Os jardins no Brasil do século XIX: Glaziou revisitado. Dissertação de mestrado, Escola de Belas Artes, Rio de Janeiro.

TOMASI, L.T. 1991. Botanical gardens of the sixteenth and seventeenth centuries. In The history of garden design: the western tradition from the Renaissance to the present day (M. Mosser \& G. Teyssot, eds.). Thams and Hudson, London, p.81-82.

UPHOF, J.C.T. 1941. Jardins botânicos: os mais importantes, antigos e modernos. A Fazenda 36: 96-97. 